\title{
Presentación del debate : Mujeres indígenas y feminismos: encuentros, tensiones $\mathrm{y}$ posicionamientos
}

\section{Mariana Daniela Gómez}

\section{(2) OpenEdition \\ Journals}

Electronic version

URL: http://journals.openedition.org/corpusarchivos/1816

DOI: $10.4000 /$ corpusarchivos.1816

ISSN: 1853-8037

\section{Publisher}

Diego Escolar

\section{Electronic reference}

Mariana Daniela Gómez, «Presentación del debate : Mujeres indígenas y feminismos: encuentros, tensiones y posicionamientos », Corpus [En línea], Vol. 7, No 1 | 2017, Publicado el 30 junio 2017, consultado el 04 mayo 2019. URL : http://journals.openedition.org/corpusarchivos/1816 ; DOI : 10.4000/corpusarchivos.1816

\section{This text was automatically generated on 4 May 2019.}




\title{
Presentación del debate : Mujeres indígenas y feminismos: encuentros, tensiones y posicionamientos
}

\author{
Mariana Daniela Gómez
}

1 Cuando me invitaron a organizar y coordinar este debate sobre los encuentros y desencuentros entre mujeres originarias o indígenas y los feminismos (y feministas) invité a todas las originarias que fui conociendo durante los últimos años (en el marco de una investigación sobre formas de participación política y procesos organizativos de mujeres indígenas en el país). También a todas aquellas investigadoras académicas que han mostrado interés por ellas, por las historias de sus pueblos y por trazar puentes para iniciar diálogos entre femineidades diversas. Yo, que me encuentro entre estas últimas y me reconozco feminista (fundamentalmente porque estoy en contra de la cultura patriarcal y racista que experimenté en mi familia, en mi barrio, en mi escuela, en la universidad, en las comunidades indígenas tobas donde trabajé durante años $\mathrm{y}$, por lo general, en el resto de la sociedad), sé de primera mano que no es nada fácil establecer esos puentes: son recientes y frágiles, y el andar de las "investigadoras/académicas/ activistas" (sean o no feministas) suele ser mirado con un poco de recelo, cautela y desconfianza por las líderes originarias. Tal vez aquí se encuentren las causas por las que muy pocas (originarias y no originarias) respondieran a la invitación que les hice llegar. Debería añadir, solo a modo de comentario, que el campo académico en el que nos movemos y forjamos posiciones las mujeres no originarias para investigar y escribir tampoco es fácil...

2 Estas dificultades y desconfianzas no han provocado, sin embargo, que desaparezca de ambos lados la curiosidad femenina, personal, cultural, política y académica. Por suerte aumenta, y lo hace al compás de la mayor visibilidad que se van forjando las mujeres originarias en distintos escenarios políticos, culturales, académicos y también jurídicos. Del lado de las feministas, el principal problema pareciera ser cómo acercarse a la realidad de las mujeres indígenas buscando ejercer la menor violencia epistémica posible 
y descentrándose de su eurocentrismo latinoamericano y de los lugares privilegiados de enunciación (si es que esto es posible). Esto se observa en general en una actitud de sumo respeto y cuidado para no opacar la voz de estas nuevas "otras" y en la apertura de espacios y lugares para que las originarias se expresen en las múltiples maneras que elijan.

Siendo así, vale la pena mencionar algunos puntos de partida o posicionamientos que vienen mostrando las mujeres originarias cuando se expresan en espacios públicos, relevantes como ejes para iniciar el debate:

4 1) Las mujeres originarias (activistas, militantes, referentes comunitarias políticas, espirituales y culturales, académicas) que participan de la discusión de las agendas globales sobre los pueblos indígenas priorizan los derechos colectivos de sus comunidades y pueblos/naciones (los derechos al territorio, la autonomía, políticas contra la discriminación étnica y racial, etc.) y entienden que sus "derechos como mujeres" no pueden definirse individualmente por fuera de los derechos colectivos de sus pueblos. Como sugiere Aída Hernández (2008, p. 51), las líderes indígenas cuestionan el paradigma occidental y hegemónico que contrapone derechos colectivos a derechos individuales y asumen que no se pueden pensar ni avanzar sobre unos sin los otros.

5 2) Una serie de discursos influencian los posicionamientos de las mujeres originarias cuando reflexionan sobre su condición de género $\mathrm{y}$, al mismo tiempo, transnacionalizan "visiones alternativas sobre los derechos de las mujeres que reivindican la cosmovisión indígena como lugar de resistencia" (Blackwell et. al. 2009, p. 27): a) los discursos provenientes de diferentes vertientes de los movimientos indígenas, b) las discusiones desarrolladas en foros y encuentros de carácter internacional concebidos especialmente para mujeres indígenas (Enlace Continental de Mujeres Indígenas, Foro Internacional de Mujeres Indígenas), y c) el desarrollo marginal de un "feminismo indígena" por parte de intelectuales y activistas mestizas e indígenas en el marco de la crítica postcolonial feminista (Hernández Castillo y Suárez Navas 2008; Rivera Zea 2008; Millán 2011 para Argentina).

6 3) La condición de género de las mujeres originarias suele ser problematizada afirmando especificidades étnicas, culturales y de clase, mediante las cuales refuerzan las marcas y experiencias históricas que las diferenciarían de las mujeres blancas y mestizas.

7 4) Por lo general, las originarias entienden la construcción cultural del género desde una teoría de la diferencia cultural (de forma esencialista) y creen que el camino para lograr una mayor igualdad de género debe construirse en compañía de los hombres y no de manera autónoma. Probablemente aquí subyace, como han señalado algunas investigadoras sobre estos temas (Hernández 2011), una concepción diferente de la "persona" y sus "derechos" que trasciende el individualismo occidental y ciertas premisas del feminismo liberal y socialista.

8 5) Para varias líderes originarias, un antecedente fundamental para elaborar un posicionamiento crítico con respecto de su condición de género ha sido la Ley Revolucionaria de las Mujeres elaborada por las zapatistas (Comandante Ramona 2001; Hernández Castillo y Elizondo 1996; Falquet 2001; Zylberberg 2004).

9 6) En muchas partes de América Latina y Central diversos grupos de mujeres indígenas comenzaron a problematizar su condición de género en colaboración con mujeres "blancas" y "mestizas" referentes de grupos religiosos de base, organizaciones civiles, organizaciones feministas, movimientos sociales, ONG y partidos de izquierda. Por lo 
tanto, es posible rastrear complejas articulaciones entre colectivos de mujeres originarias y sectores del movimiento de mujeres latinoamericano, a pesar de que el primero no persigue los objetivos feministas más comunes.

7) Cuando las líderes y referentes comunitarias acceden a discutir y mencionar cuáles son sus problemas de género que les gustaría transformar suelen señalar: la violencia de género doméstica y extra-doméstica (comunitaria, estatal, militar y paramilitar), la restricción en sus desplazamientos y movilidades, la desvalorización de ellas y de sus actividades por parte de los hombres, y las desiguales posibilidades para acceder a la educación en sus distintos niveles y a instancias de participación/formación política en comparación con los hombres.

11 Teniendo en cuenta estos 7 puntos de partida o ejes, y considerando que este debate se centrará en los encuentros y desencuentros entre las mujeres originarias y los feminismos, abajo dejamos algunos interrogantes generales y específicos, pues sabemos que los lugares de enunciación de las originarias y no originarias no son los mismos, como tampoco lo son las experiencias históricas y las biografías personales y familiares. El objetivo es que funcionen como disparadores para pensar, recordar, reflexionar, consultar bibliografía (en caso de que lo consideren necesario) y escribir. No es necesario que respondan a cada uno de ellos.

\section{Generales:}

12 ¿Qué pueden aportar los lenguajes y las categorías de los "feminismos no hegemónicos", esto es, los feminismos indígenas, populares, comunitarios, postcoloniales, descoloniales -especialmente los surgidos en México y Bolivia- para visualizar, comprender y acompañar la transformación de las realidades de las mujeres originarias?

¿Qué otras experiencias y lenguajes - que tal vez no se identifiquen como feminismos no hegemónicos pero que sí se los están apropiando las mujeres indígenas como por ejemplo el discurso de los derechos universales de las mujeres- pueden aportar en sus procesos de visibilización y demanda de derechos colectivos e individuales?

\section{Específicos para las originarias:}

¿Pueden las mujeres originarias interpelarse a sí mismas en dimensiones como el cuerpo, la sexualidad, la maternidad y el deseo sin ayuda del feminismo o sin reconocer las conquistas logradas por las luchas de las feministas en estos aspectos en las últimas décadas?

¿Les interesa interpelarse en estos aspectos más íntimos de la persona? Si es así ¿Cómo lo harían?

¿Por qué creen que les asusta el feminismo a las líderes indígenas? ¿Hasta dónde este rechazo no se basa en proyectar un estereotipo de "la mujer feminista-blanca-winkapequeñoburguesa" o de la "feminista anti-hombres"? Estos estereotipos no se corresponden con la realidad (que es mucho más variada y compleja) y dejan afuera a miles de mujeres de sectores populares que luchan contra la cultura patriarcal de sus familias, barrios, comunidades y organizaciones 
¿Serían las mujeres zapatistas y su Ley Revolucionaria lo más cercano a un feminismo indígena deseado, ya que allí se conjugarían de manera armónica y justa los derechos de las mujeres con los derechos colectivos de los pueblos indígenas?

En América Latina: ¿qué mujeres originarias están más preparadas para dar esta discusión?

\section{Específicos para las no-originarias:}

9 ¿Se encuentra el feminismo descolonial/postcolonial operando con una representación de "la mujer indígena" que tiende a abarcar solo a aquellas mujeres indígenas activistas, referentes, escritoras o académicas con las que han entrado en contacto en los últimos años? ¿Qué riesgos entraña esta postura?

Habiendo tenido la experiencia de compartir espacios y diálogos con distintas mujeres originarias en donde se manifestaron en contra de las feministas, ¿qué ideas e imágenes usted cree que las mujeres originarias deberían desarmar para poder apropiarse con mayor claridad de algunas de las conquistas y posiciones subjetivas de las feministas?

21 Invitamos a la presentación de artículos, reflexiones y ensayos en torno a los cruces entre las experiencias de mujeres originarias y los diversos feminismos en Argentina y en el resto del continente.

\section{BIBLIOGRAPHY}

Blackwell, M, Hernández Castillo, R. A., Herrera, et al. (2009). Cruces de frontera, identidades indígenas, género y justicia en las Américas. Desacatos, 21, 13-34.

Comandanta Ramona (2001). Discurso de la Comandante Ramona. En https:// mujeresylasextaorg.wordpress.com/mujeres-zapatistas/

Falquet, J. (2001). La costumbre cuestionada por sus fieles celadoras: reivindicaciones de las mujeres zapatistas. Debate Feminista, 12(24), 163-190.

Hernández Castillo, R. A. (2008). Diálogos e identidades políticas: génesis de los procesos organizativos de mujeres indígenas en México, Guatemala y Colombia. En R. A. Hernández (Coord.), Etnografías e historias de resistencia. Mujeres indígenas, procesos organizativos y nuevas identidades políticas, (pp. 45-125). México: Publicaciones de la casa chata.

Hernández Castillo, R. A. (2011). Movimientos de Mujeres Indígenas: re-pensando los derechos desde la diversidad. En G. Espinosa y A. Lau Jaiven (Coords.), Un Fantasma recorre el siglo. Luchas feministas en México 1910-1920, (pp. 309-331). México: UNAM-Xochimilco.

Hernández Castillo, R. A. y Elizondo, H. O. (1996). Las demandas de la mujer indígena en Chiapas. Revista Nueva Antropología, 15(49), 31-39. 
Hernández Castillo, R. A. y Suárez Navaz, L. (2008). Introducción. En L. Suárez Navaz y R. Aída Hernández (Eds.), Descolonizando el feminismo. Teorías y prácticas desde los márgenes, (pp. 11-30). Madrid: Cátedra.

Millán, M. (2011). Mujer Mapuche. Explotación colonial sobre el territorio corporal. En K. Bidaseca y V. Vázquez Laba (Comps.), Feminismos y Poscolonialidad. Descolonizando el feminismo desde y en América Latina, (pp. 127-136). Buenos Aires: Godot.

Rivera Zea, T. (2008). Mujeres indígenas americanas luchando por sus derechos. En L. Suárez Navaz y R. Aída Hernández (Eds.), Descolonizando el feminismo. Teorías de y prácticas desde los márgenes, (pp. 331-350). Madrid: Cátedra.

Zylberberg, V. (2004). Género, identidad y resistencia. Movimiento Zapatista y Mujeres en Chiapas. Tesis de Licenciatura en Antropología. Escuela Nacional de Antropología e Historia. México.

\section{AUTHOR}

\section{MARIANA DANIELA GÓMEZ}

Instituto de Ciencias Antropológicas, Facultad de Filosofía y Letras, Universidad de Buenos Aires (UBA) y Consejo Nacional de Investigaciones Científicas y Técnicas, Argentina Correo electrónico:marianadanielagomez35@gmail.com 